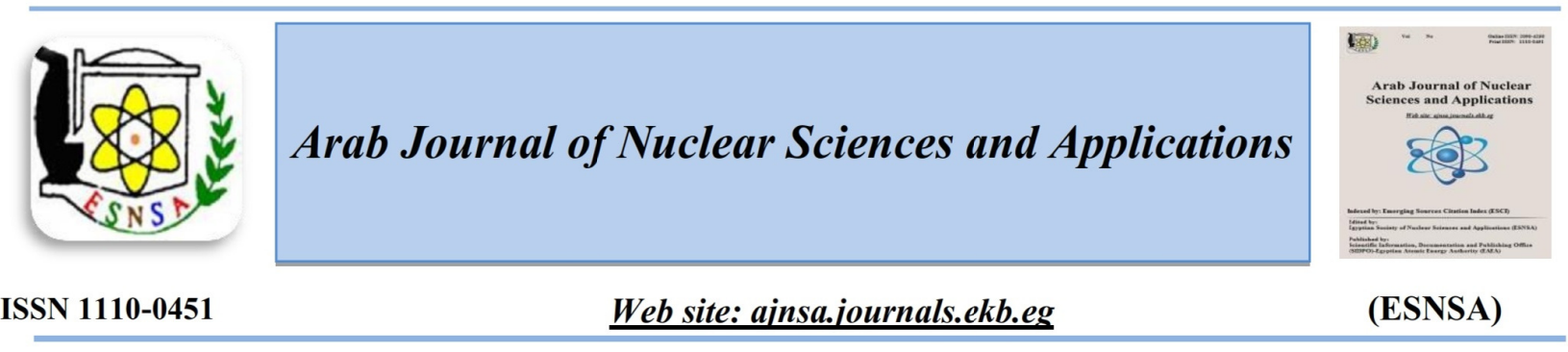

\title{
Methylene tetrahydrofolate reductase Gene Polymorphism C677T and Risk of Type two Diabetes Mellitus in Beni-Suef Governorate
}

\author{
Heba Hamdy Demellawy ${ }^{(1)}$ Hanan Mohamed Farhan ${ }^{(2)}$ Elessawi, F., Dina ${ }^{(3)}$ Mohamed S.Tawfik $^{(3)}$ \\ 1) Faculty Of Medicine Beni-Suef University \\ 2) Faculty of Medicine Beni-Suef University \\ 3) Health Radiation Research Department, National Centre for Radiation Research and Technology \\ (NCRRT), Egyptian Atomic Energy Authority (EAEA).
}

Received $28^{\text {th }}$ Sept. 2019

Accepted $22^{\text {th }}$ March

2020

\begin{abstract}
Methylene Tetrahydrofolate Reductase (MTHFR) is known to be a regulatory enzyme of homocysteine metabolism. In many ethnic groups point mutations in MTHFR gene are implicated in the pathogenesis of diabetic nephropathy (DN) and other complications of type II diabetes mellitus (T2DM). The aim of this study was to assess if MTHFR C677T gene polymorphism was one of the risk factors for the development of diabetic nephropathy as well as other complications in type 2 diabetes mellitus patients. The MTHFR C6777T polymorphisms were detected in 50 persons by PCR-RFLP. Subjects were divided into 2 groups; 30 patients with type II DM and 20 persons who were non-diabetic healthy controls. The presence of MTHFR 677T allele did not increase the risk of complications in T2DM patients. The presence of mutant genotypes CT and TT did not increase the risk of nephropathy or other complications in the subjects having a C677T mutation. Methylene Tetrahydrofolate Reductase (MTHFR) C677T gene mutation was neither associated with an increased risk of diabetic nephropathy nor other complications of type II diabetes mellitus.
\end{abstract}

Key words: diabetic nephropathy, type II diabetes mellitus, MTHFR-diabetes mellitus complications.

\section{Introduction}

Diabetes mellitus is reflected as a chronic disease that necessities ongoing medical attention and long-term patient self-management planning and support to combat acute complications and to drop the risk of chronic complications [1]. The enormity of type II diabetes mellitus (T2DM) prevalence has been escalating globally. It is portrayed as being a disease that pools both a decreased secretion of insulin hormone in addition to insulin resistance [2]. This multifaceted disease, occurring as a sequela of metabolic syndrome, is due to a complex interplay of genetic components as well as multiple environmental factors that negatively affect beta- cell tissue, insulin production, insulin effect, body contour and weight. Accompanying the increase in the occurrence of type II diabetes mellitus (DM), there is a matching rise in ensuing complications such as cardiovascular disease, retinopathy, neuropathy, and nephropathy $[3,4]$. Diabetic nephropathy (DN) is a leading cause of chronic renal affection in patients starting hemodialysis. It is accompanied by an increased risk of cardiovascular morbidity and mortality. Diabetic nephropathy has been traditionally defined by several authors as an increased rate of protein excretion in urine. Initial stages of this disease are characterized by a microscopic rise in urinary albumin excretion (UAE), also named

Corresponding author: dinaelessawi@hotmail.com

DOI: 10.21608/ajnsa.2020.17458.1277

(C) Scientific Information, Documentation and Publishing Office (SIDPO)-EAEA 
microalbuminuria or incipient DN. A more progressive type of this disease is characterized by the existence of macroalbuminuria or proteinuria. This advanced form of the disease is typically labeled as overt DN. In many instances, proteinuria and decreased estimated glomerular filtration rate (eGFR) usually occur in a congruent fashion. Traditionally speaking, eGFR has been predicted to decrease when proteinuria is evident and never beforehand. Nonetheless, it is clear today that some subjects may suffer from DN in the absence of an increased level of UAE. Approximately a tenth of patients having type II diabetes mellitus (T2DM) will suffer a decreased level of eGFR without either microalbuminuria or macroalbuminuria $[5,6]$.

Methylene Tetrahydrofolate Reductase (MTHFR) is a fundamental regulatory enzyme involved in the process of folate and homocysteine metabolism. A lack of MTHFR is accompanied by an increased level of plasma homocysteine, which is consequently linked to an increased risk of atherosclerotic vascular pathology including the disposition to nephropathy among diabetic patients [7] One of the most methodically investigated polymorphisms in the MTHFR gene is C677T [8] The C677T polymorphism transforms an alanine residue to a valine one (ALA222VAL), leading to a decreased expression of the gene in concern climaxing into a lower level of enzymatic activity. In contrast to the $677 \mathrm{CC}$ wild genotype, the 677TT homozygous and 677CT heterozygous genotypes cause a decreased level of enzymatic activity by around $70 \%$ and $40 \%$, respectively. The distribution of this polymorphism among ethnic groups is about $54.5 \%$ [9]. The objective of this study was to evaluate whether methylene tetrahydrofolate reductase (MTHFR) C677T gene polymorphism was a risk factor for the development of diabetic nephropathy in addition to other chronic complications in type II diabetes mellitus patients.

\section{Patients and Methods}

The current investigation involved a case-control type of study that was carried out in Beni-Seuf University Hospital on patients visiting the diabetes and internal medicine outpatient clinic from January 2018 to March 2018. The study conformed to the 1995 Helsinki declaration and all patients gave their informed verbal consent prior to their inclusion.
The study was conducted on 50 subjects (30 cases: 30 patients suffering from type II diabetes mellitus and 20 non-diabetic healthy subjects designated as controls). Inclusion criteria for enrollment in the patient category was based on the duration of diabetes mellitus and albumin/creatinine ratio. Exclusion criteria included patients with serious complications such as atherosclerosis, coronary heart diseases at the time of the study, patients with type 1 diabetes mellitus and pregnant females

A full medical history, thorough physical examination and comprehensive laboratory investigations were done, for both cases and controls.

\section{Routine laboratory investigations}

The following laboratory investigations were carried out on all subjects participating in the current work:

-Fasting blood sugar level and a two-hour postprandial blood sugar level.

- Hemoglobin A1c \% (HbA1c \%).

-Serum creatinine.

-Albumin/ creatinine ratio.

-Complete lipid profile (including total serum Cholesterol, serum HDL-cholesterol, serum LDL-cholesterol and se ru m Triglycerides).

\section{Special investigations}

Venous blood samples were withdrawn from every participant. Afterwards, genomic DNA was obtained using a DNA extraction kit (SigmaAldrich, USA) in line with the manufacturer's recommendations.

Assessment of C677T polymorphism in the MTHFR gene was achieved by PCR-RFLP examination in consistency with procedure settings and primer sequences elucidated earlier by Frosst et al. [7].

\section{Statistical Analysis:}

Normally distributed data are expressed as mean \pm standard deviation while abnormally distributed values are presented as the median, interquartile range). T-test was used to determine if there was a significant difference between the means and standard deviations of the two main groups.

Odds ratio statistical analysis was used as a measure of association between the presence or absence of MTHFR gene polymorphism and various diabetes mellitus complications. 
Confidence interval was used to indicate the degree of uncertainty associated with that ratio.

\section{Results}

The study was conducted on 50 persons; 30 patients with type II diabetic patients who were recruited from the diabetes outpatient clinic in Beni-Suef University hospital, and 20 non-diabetic control persons.

The patients' group (cases), included 30 patients; 7 (23.3\%) males and $23(76.7 \%)$ females, while the control group included 20 participants; 7 (35\%) males and $13(65 \%)$ females. The mean age \pm SD of cases group was 49.2 \pm 7.5 (ranging between 31-57 years), while mean $\pm \mathrm{SD}$ of controls was $45.5 \pm 11.8$ (ranging between 17-55 years). There were no statistically significant differences between the cases and controls in regard to their mean age and sex.

The mean \pm SD of diabetic duration in years was $7.1 \pm 6.4$, ranging between $1-20$ years, the mean \pm SD of body mass index (BMI) among cases was $31.1 \pm 5.0$, ranging between 19.8-40.2), while the mean \pm SD of BMI among controls was 28.6 \pm 4.9 (range 28.6 44.9$)$. There was a significant difference in BMI between cases and controls $(\mathrm{p}=0.007)$.

The routine laboratory investigations carried out in the studied groups are illustrated in Table(1).
Statistically significant differences were found between the cases and controls in regard to fasting blood sugar, 2-hour post prandial sugar, HbA1c, serum creatinine, blood urea, serum cholesterol and triglycerides $(\mathrm{p}<0.05)$.

There were no significant differences between cases and controls concerning the presence of MTHFR gene and allele.

The odds of presence of MTHFR gene and allele, were slightly higher in cases compared to the controls (1.4 and 1.2), at 95\% CI ( $\mathrm{CI}=0.38-5.03)$, but there was no significant difference between both groups, in regard to the presence of MTHFR gene and allele as evident in table (2).

With regard to complications of diabetes mellitus, there was a significant difference between cases and controls concerning the presence of diabetic complications as demonstrated in table (3).

A comparison between retinopathy, neuropathy, nephropathy in regard to MTHFR gene alleles is shown in table (4).

In the present study, no statistically significant relationship ( $p>0.05)$ was established between the presence of MTHFR mutant genotypes in the serum of diabetic patients and the development of diabetic neuropathy, diabetic retinopathy or diabetic nephropathy.

Table (1): Results of Laboratory Investigations Among Studied Groups

\begin{tabular}{|c|c|c|c|}
\hline Parameters (Mean \pm SD) & $\begin{array}{c}\text { Patients } \\
(n=30)\end{array}$ & $\begin{array}{l}\text { Control } \\
(n=20)\end{array}$ & P-value \\
\hline Fasting Blood Sugar (mg/dl) & $192.3 \pm 84.3$ & $92.2 \pm 18.5$ & $0.001 * *$ \\
\hline Two-hour Post-prandial Glucose (mg/dl) & $250.9 \pm 83.4$ & $127.0 \pm 34.1$ & $0.001 * *$ \\
\hline HbA1C (\%) & $7.8 \pm 1.7$ & $5.3 \pm 0.1$ & $0.001 * *$ \\
\hline Serum Creatinine (mg/dl). & $0.9 \pm 0.3$ & $0.8 \pm 0.2$ & $0.032 *$ \\
\hline Blood Urea (mg/dl) & $39.5 \pm 14.4$ & $30.0 \pm 5.5$ & $0.007 * *$ \\
\hline $\begin{array}{l}\text { Albumin/Creatinine Ratio } \\
\text { ( } \mu \mathrm{g} / \mathrm{mg} \text { creatinine) }\end{array}$ & $202.5 \pm 397.2$ & $>30$ & $0.001 * *$ \\
\hline Serum Cholesterol (mg/dl). & $200.4 \pm 72.9$ & $128.2 \pm 36.8$ & $0.001 * *$ \\
\hline Serum Triglycerides (mg/dl). & $186.7 \pm 85.1$ & $122.7 \pm 41.9$ & $0.003 * *$ \\
\hline
\end{tabular}

Table (2): Comparison Between Patient and Control Groups as regards Methylene Tetrahydrofolate Reductase (MTHFR) Gene

\begin{tabular}{|c|cc|c|c|c|c|}
\hline \multicolumn{2}{|c|}{ Genotype \& Allele } & $\begin{array}{c}\text { Patients } \\
(\mathbf{n = 3 0})\end{array}$ & $\begin{array}{c}\text { Controls } \\
(\mathbf{n = 2 0})\end{array}$ & P-value & $\begin{array}{c}\text { OR } \\
(\mathbf{9 5 \%} \text { CI) }\end{array}$ \\
\hline \multirow{2}{*}{$\begin{array}{c}\text { MTHFR } \\
\text { Gene }\end{array}$} & $\bullet$ & $\mathbf{C C}$ & $7(23.3)$ & $6(30)$ & Reference & Reference \\
\cline { 2 - 7 } & $\bullet$ & $\mathbf{C T}$ & $21(70)$ & $13(65)$ & 0.621 & $1.4(0.38-5.03)$ \\
\hline \multirow{2}{*}{ Allele } & $\bullet$ & $\mathbf{T}$ & $2(6.7)$ & $1(5)$ & 0.688 & $1.7(0.12-23.9)$ \\
\cline { 2 - 7 } & $\bullet$ & $\mathbf{C}$ & $35(58.3)$ & $25(62.5)$ & Reference & Reference \\
\hline
\end{tabular}

OR: Odds ratio. CI: Confidence interval.

CC, CT \& TT: Methyl Tetrahydrofolate Reductase Genotypes. C, T: Alleles. 
Table (3): Diabetic Complications Distribution Among Studied Groups

\begin{tabular}{|c|c|c|c|}
\hline & $\begin{array}{c}\text { Patient } \\
(n=30)\end{array}$ & $\begin{array}{c}\text { Control } \\
(n=20)\end{array}$ & P value \\
\hline $\begin{array}{rr}\text { Retinopathy, number } v s .(\%) \\
\bullet \quad \text { Negative } \\
\bullet \quad \text { Positive }\end{array}$ & $\begin{array}{c}17(56.7 \%) \\
13(43.3)\end{array}$ & $\begin{array}{c}20(100 \%) \\
0(0)\end{array}$ & $0.001 * *$ \\
\hline $\begin{array}{rr}\text { Neuropathy, number } v s .(\%) \\
\bullet \quad \text { Negative } \\
\bullet \quad \text { Positive }\end{array}$ & $\begin{array}{l}11(36.7 \%) \\
19(63.3 \%)\end{array}$ & $\begin{array}{c}20(100 \%) \\
0(0)\end{array}$ & $0.001 * *$ \\
\hline $\begin{array}{rr}\text { Nephropathy, number } v s .(\%) \\
\bullet \quad \text { Negative } \\
\bullet \quad \text { Positive }\end{array}$ & $\begin{array}{l}19(63.3 \%) \\
11(36.7 \%)\end{array}$ & $\begin{array}{c}20(100 \%) \\
0(0)\end{array}$ & $0.002 * * *$ \\
\hline $\begin{array}{r}\text { Others, number vs. }(\%) \\
\bullet \quad \text { Negative } \\
\bullet \quad \text { Positive }\end{array}$ & $\begin{array}{l}15(50 \%) \\
15(50 \%)\end{array}$ & $\begin{array}{c}20(100 \%) \\
0(0)\end{array}$ & $0.001 * *$ \\
\hline
\end{tabular}

*; P-value $<0.05$ (Significant).

**; P-value $<0.01$ (Highly significant).

$\mathrm{P}$-value $>0.05$ (Non-significant).

Table (4): Methylene Tetetahydrofolate Reductase gene and diabetic complications

\begin{tabular}{|c|c|c|c|c|}
\hline \multirow[b]{2}{*}{ Parameters } & \multicolumn{2}{|c|}{ Retinopathy $(\mathrm{n}=30)$} & \multirow[b]{2}{*}{$P$ value } & \multirow{2}{*}{$\begin{array}{l}\text { OR } \\
(95 \% \mathrm{CI})\end{array}$} \\
\hline & $\begin{array}{l}\text { Yes } \\
(n=13)\end{array}$ & $\begin{array}{l}\text { No } \\
(n=17)\end{array}$ & & \\
\hline $\begin{array}{ll}\text { MTHFR Gene,number } \boldsymbol{v s .} \text { (\%) } \\
\text { - } & \text { CC } \\
- & \text { CT } \\
- & \text { TT }\end{array}$ & $\begin{array}{l}2(15.4) \\
10(76.9) \\
1(7.7)\end{array}$ & $\begin{array}{l}5(29.4) \\
11(64.7) \\
1(5.9)\end{array}$ & $\begin{array}{l}0.375 \\
0.294 \\
0.844\end{array}$ & $\begin{array}{l}0.4(0.1-2.7) \\
0.5(0.13-1.8) \\
1.3(0.1-23.5)\end{array}$ \\
\hline $\begin{array}{l}\text { Allele } \\
-\quad \mathrm{C} \\
\bullet \mathrm{T}\end{array}$ & $\begin{array}{l}14(53.8) \\
12(46.2)\end{array}$ & $\begin{array}{l}21(61.8) \\
13(38.2)\end{array}$ & $\begin{array}{l}0.538 \\
0.538\end{array}$ & $\begin{array}{l}0.7(0.25-2.03) \\
1.4(0.5-3.9)\end{array}$ \\
\hline Parameters & $\begin{array}{l}\text { Neuropathy } \\
\text { Yes } \\
(n=19)\end{array}$ & $\begin{array}{l}\text { No } \\
(n=11)\end{array}$ & P-Value & $\begin{array}{l}\text { OR } \\
(95 \% \mathrm{CI})\end{array}$ \\
\hline $\begin{array}{ll}\text { MTHFR Gene, number vs. (\%) } \\
-\quad \mathrm{CC} \\
-\quad \mathrm{CT} \\
-\quad \mathrm{TT} \\
\end{array}$ & $\begin{array}{l}4(21.1) \\
14(73.7) \\
1(5.3) \\
\end{array}$ & $\begin{array}{l}3(27.3) \\
7(63.6) \\
1(9.1) \\
\end{array}$ & $\begin{array}{l}0.698 \\
0.564 \\
0.688 \\
\end{array}$ & $\begin{array}{l}0.7(0.12-3.9) \\
1.6(0.32-7.9) \\
0.55(0.03-9.8) \\
\end{array}$ \\
\hline $\begin{array}{ll}\text { Allele } & \\
- & \mathrm{C} \\
\bullet & \mathrm{T}\end{array}$ & $\begin{array}{l}22(57.9) \\
16(42.1)\end{array}$ & $\begin{array}{l}13(59.1) \\
9(40.9)\end{array}$ & $\begin{array}{l}0.927 \\
0.927\end{array}$ & $\begin{array}{l}0.9(0.32-2.7) \\
1.1(0.3-3.1)\end{array}$ \\
\hline Parameters & $\begin{array}{r}\text { Nephropathy } \\
\text { Yes } \\
(\mathbf{n}=11)\end{array}$ & $\begin{array}{c}\text { No } \\
(n=19)\end{array}$ & $P$ value & $\begin{array}{c}\text { OR } \\
(95 \% \mathrm{CI})\end{array}$ \\
\hline $\begin{array}{ll}\text { MTHFR Gene, number vs. (\%) } \\
-\quad \mathrm{CC} \\
-\quad \mathrm{CT} \\
-\quad \mathrm{TT} \\
\end{array}$ & $\begin{array}{l}2(18.2) \\
8(72.7) \\
1(9.1)\end{array}$ & $\begin{array}{l}5(26.3 \%) \\
13(68.4 \%) \\
1(5.3 \%) \\
\end{array}$ & $\begin{array}{l}0.613 \\
0.804 \\
0.688\end{array}$ & $\begin{array}{l}0.6(0.1-3.9) \\
1.2(0.23-6.35) \\
1.8(0.1-31.9)\end{array}$ \\
\hline $\begin{array}{ll}\text { Allele } & \\
\bullet & \mathrm{C} \\
\bullet & \mathrm{T}\end{array}$ & $\begin{array}{l}12(54.5) \\
10(45.5)\end{array}$ & $\begin{array}{l}23(60 \%) \\
15(39 \%)\end{array}$ & $\begin{array}{l}0.650 \\
0.650\end{array}$ & $\begin{array}{l}0.8(0.3-2.3) \\
1.3(0.44-3.7)\end{array}$ \\
\hline
\end{tabular}

CC, CT \& TT: Methyl Tetrahydrofolate Reductase Genotypes. C, T: Alleles. 


\section{Discussion}

The prevalence of type II diabetes mellitus (T2DM) has been escalating around the globe. It comprises more than $90-97 \%$ of the total number of diabetes mellitus cases in western societies, with higher incidence rates in underdeveloped countries $[1,2]$. The medical and socioeconomic load of the disease is caused by the related complications which impose vast pressures on healthcare schemes. The overpowering complications of T2DM are both macrovascular which occur as a result of accelerated atherosclerosis and microvascular complications $[3,4]$.

Diabetic nephropathy (DN) is the foremost cause of chronic renal affection. It has been classified into several stages depending on the amount of excreted protein in urine including microalbuminuria and macroalbuminuria. The cutoff values of microalbuminuria and macroalbuminuria are thought to be subjective. Patients belonging to the upper-normal range of albuminuria are at a heightened risk of progression to microalbuminuria or macroalbuminuria and they also have a higher blood pressure in comparison with subjects with normoalbuminuria. Therefore, the two main factors that pose as a risk for developing diabetic nephropathy are hyperglycemia and hypertension $[5,6]$.

This current study was conducted on 50 persons who were divided into 20 healthy control subjects and 30 type II diabetes mellitus patients enrolled from the diabetes outpatient clinic at Beni-Suef University hospitals. The study was conducted on T2DM patients who were subdivided into three groups according to the degree of albumin/ creatinine ratio (ACR); patients with normoalbuminuria, microalbuminuria and macroalbuminuria. Microalbuminuria was defined as ACR $30-300 \mu \mathrm{g} / \mathrm{mg}$. Normoalbumiuria was defined as levels below the latter range while macroalbuminuria was defined as levels above the specified range. Studies carried out by Fung et al. [10] Moczulski et al. [11] and Rahimi et al. [12] were in concordance to the current study in regard to this particular approach. There were no statistically significant differences in the sex distribution between groups participating in this study ( $\mathrm{p}=0.375)$ and this was consistent with studies carried out by Mtiraoui et al. [13] and Ukinc et al. [14].

The BMI showed no significant differences between the studied groups, which is in congruence with the studies concluded by Ukinc et al. [14] and Rahimi et al. [12]. Also, the study carried out by Mtiraoui et al. [13] did not show any significant differences between diabetic patients with and without nephropathy in regard to BMI but there was a significant difference between these two groups and the healthy control subjects.

The mean value of HbA1c did not display any statistically significant disparities between patients with or without nephropathy, although the mean value of $\mathrm{HbAlc}$ was more elevated in patients with DN in comparison with those of healthy controls. In addition, there were no significant differences observed with the patients participating in studies carried out by Mtiraoui et al. [13] and Rahimi et al. [12] regarding this factor. Contrariwise, the study that was carried out by Eroglu et al. [15] found that the mean value of $\mathrm{HbAlc}$ was significantly higher in participants suffering from DN compared to those without.

The study established a statistically significant difference when comparing groups in regard to serum creatinine levels $(\mathrm{p}=0.001)$. This was confirmed by the studies concluded by Mtiraoui et al. [13] $(\mathrm{p}<0.05)$, Eroglu et al. [15] $(\mathrm{p}=0.012)$. However, the study carried out by Rahimi et al. [12] showed a statistically significant difference that was confined only to T2DM patients versus healthy control groups $(\mathrm{p}<0.01)$.

In the present study, on comparing MTHFR C677T genotypes (CC, CT and TT) among the studied groups, it was revealed that the mutation was not associated with a heightened risk of nephropathy. The incidence of mutant genotypes $(\mathrm{CT}+\mathrm{TT})$ was not proved to be significantly higher in diabetic patients complicated with macroalbuminuria in comparison with those with normoalbuminuria $\quad(78.6 \%$ and $49.3 \%$ respectively). This was contradictory to a study completed in Tunisia by Mtiraoui et al., [13] who found that the mutant genotypes CT and TT were more prevalent in patients suffering from DN. Also, the current results were not in agreement with those observed during a study carried out in Egypt by El-Baz et al. [8], who found that the CT and TT genotypes were more frequent in T2DM patients with DN in comparison with subjects without, $(p<0.01)$. In agreement with the present work, an investigation that was carried out on a Turkish population revealed that the genotype frequencies were $2.1 \%, 46.6 \%$ and $55.3 \%$ for TT, $\mathrm{CT}$ and TC respectively in diabetic patients with 
nephropathy against $10.7 \%, 44.6 \%$ and $44.6 \%$ for TT, CT and CC respectively in those without nephropathy with no statistically significant differences ( $p>0.05)$ [14]. Furthermore, two studies conducted in Japan proved that there was no risk associated between MTHFR C677T mutation and DN [16,17] which were in concordance with the findings derived from the present study. This discrepancy may be explained by the differences in the environmental factors and ethnic or genetic deviations.

The data of the current study did not correspond with that of a study carried out on Iranian populations, where the incidence of $(\mathrm{CT}+\mathrm{TT})$ was significantly higher in patients with macroalbuminuria $(60.3 \%)$ compared to those with normoalbuminuria (37.5\%) [12].

On comparing the outcomes of the current study with those of other studies, it was confirmed that there was a partial disparity with the results found by a study completed in Poland by Moczulski et al. [11] who discovered that $(\mathrm{CT}+\mathrm{TT})$ genotypes frequency was significantly higher in patients with macroalbuminuria compared to individuals with normoalbuminuria. However, this finding was limited only to the male group of patients $(\mathrm{p}=0.02)$. They clarified this by pointing out to the increased prevalence of the -cigarette- smoking persons among males. In the present study, it was found that T2DM patients with C677T mutation, were more susceptible to developing macroalbuminuria and the risk was found to be 3.7 times higher in comparison to patients with normoalbuminuria. The risk of developing DN and macroalbuminuria in the presence of MTHFR gene mutation was 2.4 times higher than risk of developing the same condition in the absence of this mutation. This was consistent with other studies. In Tunisia the TT genotype was associated with a 2.49 fold increased risk of developing macroalbuminuria and the OR for the CT genotype was 3.6 [13]. Among Iranian populations the C677T mutation was associated with a 2.53-fold increased risk for the development of macroalbuminria [12]. In an Egyptian study the aforementioned mutation was associated with a 6.4-fold increased risk for the development of macroalbuminuria [8]. This was in partial agreement with a study completed in Poland by Moczulski et al. [11] .The C677T mutation was associated with a 2.4-fold increased risk for development of macroalbuminuria but this was confined to male patients only.
As far to the allele frequency, the mutant allele MTHFR 677T did not pose as a higher risk in patients with macroalbuminuria compared to patients with normoalbuminuria. The $677 \mathrm{~T}$ allele enhanced the risk for macroalbuminuria 2.6 folds against patients with normoalbuminiria. This did not appear to be in congruence with the study completed by Sun et al. [18] who reported that in a consort of studied Chinese populations, the $677 \mathrm{~T}$ allele represent a risk factor for the development of DN (OR=1.83). Mtiraoui et al. [13] and El-Baz et al. [8] revealed in their studies that the 677T allele was significantly more frequent in patients with DN $(p<0.001)$ and it increased the risk of nephropathy 9.47 folds and 5.9 folds for the former and latter studies respectively. Also, Rahimi et al. [12] noted that the 677T allele was significantly more frequent in patients with macroalbuminuria compared to patients with normoalbuminuria $(p<0.001, O R=3)$. Nemr et al. [19] revealed that the $677 \mathrm{~T}$ allele posed as a risk factor for diabetic nephropathy in Lebanese populations $(\mathrm{OR}=2.43)$ while Chen et al. [20] stated that the 677T allele was considered to pose a risk for the occurrence of diabetic nephropathy in Asian populations $(\mathrm{OR}=2.19)$

On the other hand, the results of the current study seemed to be in agreement with those accomplished by Eroglu et al. [15] who did not find any discrepancy in MTHFR 677T allele frequency between diabetic patients with or without nephropathy $(\mathrm{p}>0.05)$. They concluded that the MTHFR gene mutation was not linked to the occurrence of diabetic nephropathy in diabetic Turkish patients.

\section{Conclusions}

Methylene tetrahydrofolate reductase (MTHFR) C677T gene mutation was neither associated with an increased risk of overt diabetic nephropathy nor any other complications in the studied section of participants suffering from type II diabetes mellitus residing within Beni-Suef governate.

\section{Recommendations}

1. Performing the same study protocol on a larger group to increase the precision of the statistical analysis.

2. Studying other polymorphisms affecting the MTHFR gene as A1298C to detect if it has a synergistic effect with C677T 
polymorphism on the development of diabetic nephropathy.

3. Further analysis of DNA samples that were positive for the MTHFR C677T mutation using DNA sequencing technique to obtain more accurate results

\section{References}

1. American Diabetes Association (2019). Standards of Medical Care in Diabetes Abridged for Primary Care Providers. Clin Diabetes ;37(1):11-34

2. Stumvoll, M, Goldstein, BJ and van Haeften, TW. (2005): type 2 diabetes: principles of pathogenesis and therapy, Lancet365, 13331346.

3. Chawla A, Chawla R, Jaggi S (2016) Microvasular and macrovascular complications in diabetes mellitus: Distinct or continuum? Indian J Endocrinol Metab.;20(4):546-51.

4. Alwin Robert A, Al Dawish MA (2019). Microvascular complications among patients with diabetes: An emerging health problem in Saudi Arabia. Diab Vasc Dis Res.:1479164118820714.

5. Alicic RZ, Rooney MT, Tuttle KR (2017). Diabetic Kidney Disease: Challenges, Progress, and Possibilities. Clin J Am Soc Nephrol. 7;12(12):2032-2045.

6. Zelmanovitz T, Gerchman F, Balthazar, AP, Thomazelli, FC, Matos, JD and Canani LH. (2009): Diabetic nephropathy, Diabetol Metab Syndr1, 10.

7. Frosst $\mathrm{P}$, Blom HJ, Milos $\mathrm{R}$, Goyette $\mathrm{P}$, Sheppard CA, Matthews RG, et al. (1995). A candidate genetic risk factor for vascular disease: a common mutation in methylenetetrahydrofolate reductase. Nat Genet:; 10:111-113.

8. El-Baz R, Settin A, Ismaeel A, Khaleel AA, Abbas, T, TOLBE W, Abd Allah W and Sobh MA. (2012): MTHFR C677T, A1298C and ACE I/D polymorphisms factors as risk factors for diabetic nephropathy among type 2 diabetic patients, J Renin Angiotensin Aldosterone Syst13, 472-477.

9. AbdRaboh NR, Badr S, Ali S. (2015): Prevalence of methylenetetrahydrofolate reductase C677T and A1298C polymorphisms in Egyptian patients with type 2 diabetes mellitus, Egy J Medical Human Genetics 14, 87-93.

10. Fung MM, Salem RM, Lipkowitz MS, Bhatnagar V, Pandey B, Schork NJ, O'Connor
DT (2012); AASK Study Investigators.

Methylenetetrahydrofolate reductase

(MTHFR) polymorphism A1298C

(Glu429Ala) predicts decline in renal function over time in the African-American Study of Kidney Disease and Hypertension (AASK) Trial and Veterans Affairs Hypertension Cohort (VAHC). Nephrol Dial Transplant.;27(1):197-205.

11. Moczulski D, Fojcik H, ZukowskaSzczechowska E, Szydlowska I, and Grzeszczak W. (2003): effects of the C677T and A1298C polymorphisms of the MTHFR gene on the genetic predisposition for diabetic nephropathy, Nephrol Dial Transplant18, 15351540 .

12. Rahimi M, Hasanvand A, Rahimi Z, VaisiRaygani, A, Mozafari H, Rezaei M, Zargooshi J, Najafi F, and Shakiba E. (2010): Synergistic effects of the MTHFR C677T and A1298C polymorphisms on the increased risk of macroalbuminuria and progression of diabetic nephropathy among Iranians with type 2 diabetes mellitus, Clin Biochem43, 1333-1339.

13. Mtiraoui, N, Ezzidi, I, Chaieb M, Marmouche, H, Aouni Z, Chaieb A, Mahjoub T, Vaxillaire M, and Almawi W. (2007): MTHFR C677T and A1298C gene polymorphisms and hyperhomocysteinemia as risk factors of diabetic nephropathy in type 2 diabetes patients, DiabetesRes Clin Pract 75, 99-106.

14. Ukinc, Ersoz, Karahan, Eminagaoglu, Hacihasanoglu, Yilmaz, Kocak, (2009): Methyltetrahydrofolate reductase C677T mutation hyperhomocysteinemia factor for diabetic nephropathy, Endocrine36, 255-261.

15. Eroglu Z, Erdogan M, Tetik A, Karadeniz M, Cetinalp S, Kosova, B, Gunduz C, Ozgen AG and Yilmaz C. (2007): the relationship of the methylenetetrahydrofolate reductase C677T gene polymorphism in Turkish type 2 diabetic patients with and without nephropathy, Diabetes Metab Res Rev;23: 621-624.

16. Yoshioka K, Yoshida T, Umekawa T, Kogure A, Takakura $\mathrm{Y}$, Toda $\mathrm{H}$ and Yoshikawa $\mathrm{T}$. (2004): Methylenetetrahydrofolate reductase GENE polymorphism IS NOT related TO diabetic nephropathy IN Japanese TYPE 2 diabetic patients, Diabet Med21, 1051-1052.

17. Maeda M, Yamamoto I, Fukuda M, Motomura T, Nishida M, Nonen S, Fujio Y, Kasayama S and Azuma J. (2008): MTHFR gene polymorphism is susceptible to diabetic retinopathy but not to diabetic nephropathy in

Arab J. Nucl. Sci. \& Applic. Vol. 53, No. 2 (2020) 
Japanese type 2 diabetic patients, J Diabetes Complications22, 119-125.

18. Sun J, Xu Y, Zhu Y and Lu H. (2004): Genetic polymorphism of ethylenetetrahydrofolate reductase as a risk factor for diabetic nephropathy in Chinese type 2 diabetic patients, Diabetes Res Clin Pract64, 185-190.

19. Nemr R, Salman RA, Jawad LH, Juma EA, Keleshian, SH and Almawi, WY (2010): Differential contribution OF MTHFR C677T variant to the risk of diabeticnephropathy in Lebanese and Bahraini Arabs, clin chem lab Med48, 1091-1094.

20. Chen H, Wei F, Wang L, Wang Z, Meng J, Jia L, Sun G, Zhang R, Li B, Yu H, Pang H, Bi X, Dong H, Jiang A and Wang L. (2015). MTHFR gene C677T polymorphism and type 2 diabetic nephropathy in Asian populations: a meta-analysis. Int $J$ Clin Exp Med. 15;8(3):3662-3670. 